\title{
Cost Effective Solution for a Shunt Hybrid Filter Using Enhanced Current Controller
}

\author{
Y. Lalitha Kameswari ${ }^{1}$, O. Chandra Sekhar ${ }^{2}$ \\ ${ }^{1}$ Electrical and Electronics Engineering Dept, NRI Institute of Technology, Agiripalli, JNTUK, India \\ ${ }^{2}$ Electrical and Electronics Engineering Dept, KLEF, AP, India
}

\begin{tabular}{l}
\hline Article Info \\
\hline Article history: \\
Received Feb 17, 2018 \\
Revised Sep 2, 2018 \\
Accepted Sep 13, 2018 \\
\hline
\end{tabular}

Keyword:

SHE PWM

APF

LQR

SHF

PWM

\begin{abstract}
The increasing demand of energy and development of distributed generation systems have led to great progress in medium voltage high-power inverters. On the other side, due to more intransigent regulations in the area of power quality and appearance of new grid codes, which limit the harmonics' amounts in ac grids, special attention has to be made to restrict the harmonics. The recently proposed selective harmonic mitigation pulse width modulation method reduces the values of specific harmonics to meet the grid codes, instead of making them zero. In this way, there are much more solutions for mitigating the same harmonics which in the Selective Harmonic Eliminated Pulse-Width Modulation (SHEPWM), are completely eliminated. The SHMPWM was first introduced in, where a waveform having $750 \mathrm{~Hz}$ switching frequency was employed to mitigate harmonics up to 49th to satisfy the grid codes EN 50160 and CIGRE WG 36-05 without using any filtering system. In this contribution a solution to the parallel resonance problem that can be present in practical applications of shunt Active Power Filter (APF) compensation is proposed. The proposed solution involves turning the shunt APF scheme of compensation into a Shunt Hybrid Filter (SHF) configuration. A Linear Quadratic Regulator (LQR)-based switching controller was specifically designed for this hybrid scheme of compensation, maintaining stringent performance requirements on the tracking of filtering currents and the draining of the harmonic ripple currents.
\end{abstract}

Copyright $\left({ }_{0} 2018\right.$ Institute of Advanced Engineering and Science. All rights reserved.

\section{Corresponding Author:}

Y. Lalitha Kameswari,

Research Scholar, Electrical and Electronics Engineering Department,

Koneru Lakshmaiah Education Foundation,

Green Fields, Guntur District, Vaddeswaram, Andhra Pradesh, India.

Email: saiproject14@gmail.com

\section{INTRODUCTION}

With the continuous increase in the incorporation of nonlinear loads in the power network, the harmonic distortion of voltage and current waveforms, among other power quality problems, has become a great concern. This paper focuses on the use of shunt filtering techniques such as shunt Active Power Filter (APF) and shunt hybrid filter (SHF), to mitigate harmonic distortion and to compensate reactive power. In conventional inverters which use sinusoidal pulse width modulation, there are heavy losses due to presence of harmonics [1]. Upcoming smart grid paradigm enabling maximum power throughputs and nearinstantaneous control of voltages and currents in all links of the power system chain [2]. The series capacitor provides the majority of the power pulsation decoupling through a wide voltage swing, and the buffer converter only needs to process a small fraction of the total power of the entire architecture, allowing a very small active circuit volume and very high system efficiency [3]. Inverter effectiveness is evaluated by comparing the performance based on SHE PWM and based on the conventional constant switching frequency PWM technique [4]. By installing DG in the transmission system, voltage stability and voltage profile can be 
improved, while losses can be minimized [5]. In particular, the shunt APF has been demonstrated to be an appropriated tool for the mitigation of harmonic currents and reactive power compensation [6]-[15]. The shunt APF can be modeled as a controlled current source that supplies a compensation current in parallel with the nonlinear load. The main components of a shunt APF are: a reference current generator, a switching current controller based on a pulse-width modulation (PWM) technique, a power electronic converter (usually a voltage-source-type PWM inverter), and a dc voltage controller (PI controller). Usually, the modulation technique used when modeling the shunt APF is the hysteresis-band current controller, due to its fast dynamic response and its easy implementation [16]-[18].

The path should be provided to drain this high frequency ripple current; this goal could be achieved with a LC ripple-filter [19] or a compensator-passive filter structure designed for this particular purpose [20]. The necessity of adequate development an application of techniques to solve potential problems of resonance and harmonic distortion in diverse electrical networks has been stressed in more recent contributions [21][23]. In [24] frequency scan and modal analysis methods are applied for harmonic distortion and system resonances identification in wave power plant applications, so that appropriate correction measures can be timely undertaken. A distributed series/hybrid-shunt compensation technique is proposed in [25] for harmonic mitigation in industrial/commercial facilities. The main aim of this paper is to provide a strong and high quality scheme of compensation, e.g., shunt filtering, when applied to non-stiff systems.

The proposed control is good enough to provide the following goals: (1) To provide a sound solution to the parallel resonance problem that can be present in shunt APF compensation, (2) To allow the correct shunt filtering compensation, (3) To avoid the propagation of the harmonic ripple current into the electric network, (4) To reduce, as much as possible, the KVA rating of the APF.

\section{RESEARCH METHOD}

\subsection{Shunt hybrid filter - parallel resonance phenomenon}

A major drawback of active power filters is their high rating, e.g. up to $80 \%$ of the nonlinear load in some practical applications [26]. The problems emerge when the APF becomes a costly solution for harmonic current mitigation and reactive power compensation. Due to economic concerns and problems associated with insulation, as well as series or parallel connection of switches [27], different structures of hybrid filter have evolved as a cost effective solution for the compensation of nonlinear loads [28]-[29]. The hybrid filter topology presented in this paper consists of a shunt APF, and a shunt capacitor bank acting as a reactive power compensator. For this compensation scheme, the shunt APF placed to perform harmonic elimination and reactive power compensation is not included in its compensation mechanism.

\subsection{Shunt hybrid filter control}

The LQR method is a powerful technique for designing controllers for complex systems that have stringent performance requirements. The LQR method seeks to find the optimal controller that minimizes a given cost function. This cost function is parameterized by two matrices, $\mathrm{Q}$ and $\mathrm{R}$, that weight the state vector and the system input, respectively. A LQR switching controller is designed to be able to generate the control signals of the voltage source inverter of the shunt APF under the SHF compensation scheme. It can be observed how the reference current generator and the LQR-based switching current controller are incorporated together to complete the proposed control strategy for the SHF compensation scheme. The flow chart of the LQR calculations to obtain the feedback gain matrix K. Given a set of weighting matrices, Q and $\mathrm{R}$, the process in the calculation of matrix $\mathrm{K}$ becomes simple. Most of the times, the weighting matrix $\mathrm{Q}$ reflects the importance of the states to be controlled and the selection of an appropriate value of $\mathrm{R}$ has to be chosen to provide the control effort of the system and to obtain a finite time convergence of the regulator. Once the LQR algorithm is solved, and the feedback matrices are obtained.The reference current generator to be used by the APF is implemented according with [5], and is given by,

$$
\begin{aligned}
& \mathrm{i}_{\mathrm{fa}}^{*}(\mathrm{t})=\mathrm{i}_{\mathrm{la}}(\mathrm{t})-\frac{2\left(\mathrm{P}_{\mathrm{T}}+\mathrm{P}_{\text {loss }}\right)}{\mathrm{U}_{\mathrm{T}}} \operatorname{Sin}\left(\omega \mathrm{t}+\phi_{\mathrm{a} 1}\right) \\
& \mathrm{i}_{\mathrm{fb}}^{*}(\mathrm{t})=\mathrm{i}_{\mathrm{lb}}(\mathrm{t})-\frac{2\left(\mathrm{P}_{\mathrm{T}}+\mathrm{P}_{\text {loss }}\right)}{\mathrm{U}_{\mathrm{T}}} \operatorname{Sin}\left(\omega \mathrm{t}+\phi_{\mathrm{a} 1}-\frac{2 \pi}{3}\right) \\
& \mathrm{i}_{\mathrm{fc}}^{*}(\mathrm{t})=\mathrm{i}_{\mathrm{lc}}(\mathrm{t})-\frac{2\left(\mathrm{P}_{\mathrm{T}}+\mathrm{P}_{\text {loss }}\right)}{\mathrm{U}_{\mathrm{T}}} \operatorname{Sin}\left(\omega \mathrm{t}+\phi_{\mathrm{a} 1}+\frac{2 \pi}{3}\right)
\end{aligned}
$$

where $i_{f k}^{*}(t)$ is the reference filtering current of phase $k, i_{l k}(t)$ is the line current of phase k, e.g. in this example it corresponds to the load current drawn by the combination of the linear unbalanced load current 
and the rectifier load current; the subscript $\mathrm{k}$ represents the phases $\mathrm{a}, \mathrm{b}$ or $\mathrm{c}$, respectively. $\mathrm{P}_{\mathrm{T}}$ is the total active power delivered to the load, $\mathrm{U}_{\mathrm{T}}$ is the sum of the peak value of the source voltages uk, /a1 is the phase angle of the fundamental component of the load voltage at phase a, and $\mathrm{x}$ is the angular speed at fundamental frequency f of $60 \mathrm{~Hz}$. The capacitor reactance and capacitance are calculated as

$$
\begin{aligned}
& X_{c f}=\frac{V_{L L}^{2}}{Q_{3 \phi}} \\
& C_{f}=\frac{1}{\omega X_{c f}}
\end{aligned}
$$

where $\mathrm{X}_{\mathrm{Cf}}$ is the capacitive reactance, $\mathrm{V}_{\mathrm{LL}}$ is the line-to-line rms voltage, and $\mathrm{C}_{\mathrm{f}}$ is the capacitance per phase.

Parallel resonance phenomenon of Load voltages and source currents: to identify the possible resonance problem, an analysis using the equivalent circuit of the electric system for phase a is performed. The linear load impedance is also included in the analysis. The equivalent impedance of the circuit at any harm harmonic order $h$ is given by,

$$
\mathrm{Z}_{\mathrm{a}}=\frac{1}{\left(1 /\left(\mathrm{R}_{\mathrm{s}}+\mathrm{jh} \omega \mathrm{L}_{\mathrm{s}}\right)\right)+\left(1 /\left(\mathrm{R}_{\mathrm{a}}+\mathrm{jh} \omega \mathrm{L}_{\mathrm{a}}\right)\right)+\left(1 /\left(-\mathrm{j} \frac{1}{\mathrm{~h} \omega \mathrm{C}_{\mathrm{f}}}\right)\right)}
$$

The test system of Figure 1 was implemented in Matlab/Simulink and the simulation results are shown in Figure 3. Figure 3(a) illustrates the load voltages; once the shunt APF is switched on after one period. Discordant waveforms appear, and this behavior may be caused by a resonance condition produced by the harmonic interaction of the APF, the capacitor bank and the load. Consequently, the same situation is presented in the source current waveforms of Figure 3(b).

\section{LQR-SWITCHING CONTROLLER}

For the designed LQR-based switching controller the optimum control of the system is based on minimizing the performance index of the form [12],

$$
J=\int_{0}^{\infty}\left\{\left(w-w_{r e f}\right)^{T} Q\left(w-w_{r e f}\right)+u^{T} R u\right\} d t
$$

where $\mathrm{w}$ is the state vector and $\mathrm{w}_{\text {ref }}$ is a desired reference state vector, $\mathrm{Q}$ is a Hermitian matrix or a symmetric positive semi-definite matrix, $\mathrm{R}$ is a symmetric positive definite matrix. For this particular case, $\mathrm{R}$ is scalar and sets a penalty on the maximum control action, $\mathrm{m}$ is the optimal control law and $\mathrm{T}$ is the transpose operator. The minimization of the cost function results in a feedback control of the form

$$
\mathrm{m}=-\mathrm{K}\left(\mathrm{w}-\mathrm{w}_{\mathrm{ref}}\right)
$$

where the gain matrix $\mathrm{K}$ is obtained by the solution of the steadystate Riccati equation [7]. Once a suitable gain matrix $\mathrm{K}$ is selected, the switching control is obtained from [12],[15]:

$$
\mathrm{m}=-\operatorname{hys}\left(\mathrm{K}\left(\mathrm{w}-\mathrm{w}_{\mathrm{ref}}\right)\right)
$$

where the hys function is defined by

$$
\begin{aligned}
& \text { if } \mathrm{K}\left(\mathrm{w}-\mathrm{w}_{\text {ref }}\right)>\frac{\Delta_{\mathrm{i}}}{2} \text { then hys }\left(\mathrm{K}\left(\mathrm{w}-\mathrm{w}_{\text {ref }}\right)\right)=1 \\
& \text { else if } \mathrm{K}\left(\mathrm{w}-\mathrm{w}_{\text {ref }}\right)<\frac{\Delta_{\mathrm{i}}}{2} \text { then hys }\left(\mathrm{K}\left(\mathrm{w}-\mathrm{w}_{\text {ref }}\right)\right)=-1
\end{aligned}
$$

This technique is called switching band tracking control in [12], and the selection of Di determines the switching frequency while tracking the reference. The equivalent circuit of the hybrid filter compensation scheme, where the combination of both linear and nonlinear loads is represented by a series RL equivalent load. The state vector $\mathrm{x}$ and the state-space equation are obtained from the analysis.

$$
x=\left[i_{1} i_{2} i_{3} i_{4}\right]^{T}
$$




$$
\dot{\mathrm{x}}=\left[\begin{array}{cccc}
-\frac{\mathrm{R}_{\mathrm{s}}}{\mathrm{L}_{\mathrm{s}}} & 0 & 0 & -\frac{1}{\mathrm{~L}_{\mathrm{s}}} \\
0 & -\frac{\mathrm{R}_{\mathrm{f}}}{\mathrm{L}_{\mathrm{f}}} & 0 & -\frac{1}{\mathrm{~L}_{\mathrm{f}}} \\
0 & 0 & -\frac{\mathrm{R}_{\mathrm{eq}}}{\mathrm{L}_{\mathrm{eq}}} & -\frac{1}{\mathrm{~L}_{\mathrm{eq}}} \\
\frac{1}{\mathrm{C}_{\mathrm{f}}} & \frac{1}{\mathrm{C}_{\mathrm{f}}} & -\frac{1}{\mathrm{C}_{\mathrm{f}}} & 0
\end{array}\right] \mathrm{x}+\left[\begin{array}{c}
\frac{1}{\mathrm{~L}_{\mathrm{s}}} \\
0 \\
0 \\
0
\end{array}\right] \mathrm{u}_{\mathrm{s}}+\left[\begin{array}{c}
0 \\
\frac{\mathrm{V}_{\mathrm{dc}}}{\mathrm{L}_{\mathrm{s}}} \\
0 \\
0
\end{array}\right] \mathrm{m}
$$

For convenience, the estate vector $\mathrm{x}$ can be transformed into a new state vector $\mathrm{w}$, which is expressed in terms of the local variables of compensation and/or the control variables, e.g., the filtering current if , the current trough the capacitor ic, the terminal voltage of the capacitor uc and the load current il. From the relationship between the state vector $\mathrm{x}$ in (11) and the new state vector $\mathrm{w}$ is observed. The state transformation is finally made by using the transformation matrix $\mathrm{V}$ as shown in (13),

$$
\begin{aligned}
& \mathrm{w}=\left[\begin{array}{c}
\mathrm{i}_{\mathrm{f}} \\
\mathrm{i}_{\mathrm{c}} \\
\mathrm{u}_{\mathrm{c}} \\
\mathrm{i}_{\mathrm{l}}
\end{array}\right]=\left[\begin{array}{cccc}
0 & 1 & 0 & 0 \\
1 & 1 & -1 & 0 \\
0 & 0 & 0 & 1 \\
0 & 0 & 1 & 0
\end{array}\right]\left[\begin{array}{l}
\mathrm{i}_{1} \\
\mathrm{i}_{2} \\
\mathrm{i}_{3} \\
\mathrm{u}_{\mathrm{c}}
\end{array}\right]=\mathrm{V}_{\mathrm{x}} \\
& A=\left[\begin{array}{cccc}
-\frac{\mathrm{R}_{\mathrm{f}}}{\mathrm{L}_{\mathrm{f}}} & 0 & -\frac{1}{\mathrm{~L}_{\mathrm{f}}} & 0 \\
\frac{\mathrm{R}_{\mathrm{s}}}{\mathrm{L}_{\mathrm{s}}}-\frac{\mathrm{R}_{\mathrm{f}}}{\mathrm{L}_{\mathrm{f}}} & -\frac{R_{f}}{L_{s}} & -\frac{1}{\mathrm{~L}_{\mathrm{s}}}-\frac{1}{\mathrm{~L}_{\mathrm{f}}}-\frac{1}{\mathrm{~L}_{\mathrm{eq}}} & -\frac{\mathrm{R}_{\mathrm{s}}}{\mathrm{L}_{\mathrm{s}}}+\frac{\mathrm{R}_{\mathrm{f}}}{\mathrm{L}_{\mathrm{f}}} \\
0 & \frac{1}{\mathrm{C}_{\mathrm{f}}} & 0 & 0 \\
0 & 0 & \frac{1}{\mathrm{~L}_{\mathrm{eq}}} & -\frac{\mathrm{R}_{\mathrm{eq}}}{\mathrm{L}_{\mathrm{eq}}}
\end{array}\right] ; \gamma_{1}=\left[\begin{array}{c}
0 \\
\frac{1}{\mathrm{~L}_{\mathrm{s}}} \\
0 \\
0
\end{array}\right] ; \gamma_{2}=\left[\begin{array}{c}
\frac{\mathrm{U}_{\mathrm{dc}}}{\mathrm{L}_{\mathrm{f}}} \\
\frac{\mathrm{U}_{\mathrm{dc}}}{\mathrm{L}_{\mathrm{f}}} \\
0 \\
0
\end{array}\right]
\end{aligned}
$$

For the control law represented by (8), it is assumed that we have full control over $\mathrm{m}$ and the switching control is based on a linear combination of multiple states [15]. For most realistic applications, the LQR problem is solved via a computational package, such as Matlab. The Matlab command lqrðK; Q; RP, with $1 / 41 \mathrm{~b} 2$, solves the LQR problem and the associated Riccati equation. This command calculates the matrix of optimum feedback control $\mathrm{K}$, so that the control feedback law (8) minimizes the performance index (7) subject to (14). Most of the times, the weighting matrix Q reflects the importance of the states to be controlled and the selection of an appropriate value of $\mathrm{R}$ has to be chosen to provide the control effort of the system and to obtain a finite time convergence of the regulator [12]. An alternative for the tuning decision of the weighting matrices is to analyze the step response of the system in order to jump-start the learning curve necessary to select $\mathrm{Q}$ and $\mathrm{R}$ and be able to apply the LQR design method to a practical problem. Once the LQR algorithm is solved, and the feedback matrices are obtained, the implementation would proceed with no further calculations of the LQR algorithm, unless the circuit and/or load conditions are changed.

\section{RESULTS AND ANALYSIS}

The Shunt Active Power Filter is implemented in MATLAB is shown in Figure 1 and the corresponding non linear Load is shown in Figure 2 and results are described. For instance, the weighting matrix to minimize the performance index of the LQR problem is selected as Q $1 / 4$ diag ${ }^{1} 1 / 2251030 \mathrm{P}$, where diag stands for diagonal matrix, and R $1 / 4$ 0:01. Although the LQR switching band current controller is claimed to be robust, and sometimes, only the calculation of the feedback matrix of a single-phase is performed and the results used for the other two phases, for this case study, we have decided to calculate the reduced feedback gain matrices for each phase a, b, c, according the flow chart. The resulting feedback matrices for each phase are given as,

$$
\begin{aligned}
& K_{a}=\left[\begin{array}{lll}
49.9468 & 9.3787 & 34.5637
\end{array}\right] \\
& K_{b}=\left[\begin{array}{lll}
49.9460 & 9.3795 & 34.7046
\end{array}\right] \\
& K_{c}=\left[\begin{array}{lll}
49.9450 & 9.3805 & 34.7665
\end{array}\right]
\end{aligned}
$$

The results obtained from the simulation with Matlab/Simulink are shown in Figure 3. It can be observed that now, both the load voltages shown in Figure 3(a), and the source currents shown in Figure 3(b), 
become balanced and free of harmonics once the shunt APF goes into operation at one cycle of simulation. The THD index for load voltages and source currents is null. In addition, the source currents are placed in phase with the load voltages, thus compensating the reactive power and achieving a unity load power factor. In similar way, from Figure 3(a), Figure 3(b) and Figure 3(c), that there is not harmonic ripple contamination into the electric network. The high-frequency ripple current has been drained-out directly through the capacitor branch avoiding its propagation into the electric network. Most importantly, the parallel-resonance problem. This goal has been achieved despite that the frequency response of the electric system is the same. The shunt APF current injected at phase $\mathrm{c}$ is illustrated in Figure 3(d). As a comparison exercise please observe the current injection in phase $c$ of Figure 3(d) and compare it to the current injection shown in Figure 3(d), which is the current injected when the compensation of reactive power was planned to be achieved by the shunt APF. It can be also noticed that the ripple current is now smaller in amplitude. For this case, the three-phase rams filtering current was $8.54 \mathrm{~A}$, giving a KVA rating of the APF of 2.6 KVA. It becomes clear that the reactive power compensation using the capacitor bank has reduced the necessary KVA rating of the APF. The reduction was approximately $1.8 \mathrm{KVA}$, from $4.4 \mathrm{KVA}$ to $2.6 \mathrm{KVA}$, which represents a remarkable $41 \%$ size reduction of the power electronic converter needed for the shunt APF. It is as well important to remark that for each particular case, the reduction of the necessary KVA rating in the shunt APF converter will depend on the amount of reactive power compensation to be achieved with the capacitor bank during the process of transforming the shunt APF compensation scheme into the SHF compensation scheme. The power flows during the shunt hybrid filter compensation. Now the capacitor bank is supplying the reactive power consumed by the load. As a consequence of a better tracking control over the filtering currents, the losses have been significantly reduced. The power losses in the shunt APF were reduced by 62\%, i.e. from $184 \mathrm{~W}$ to $70 \mathrm{~W}$.

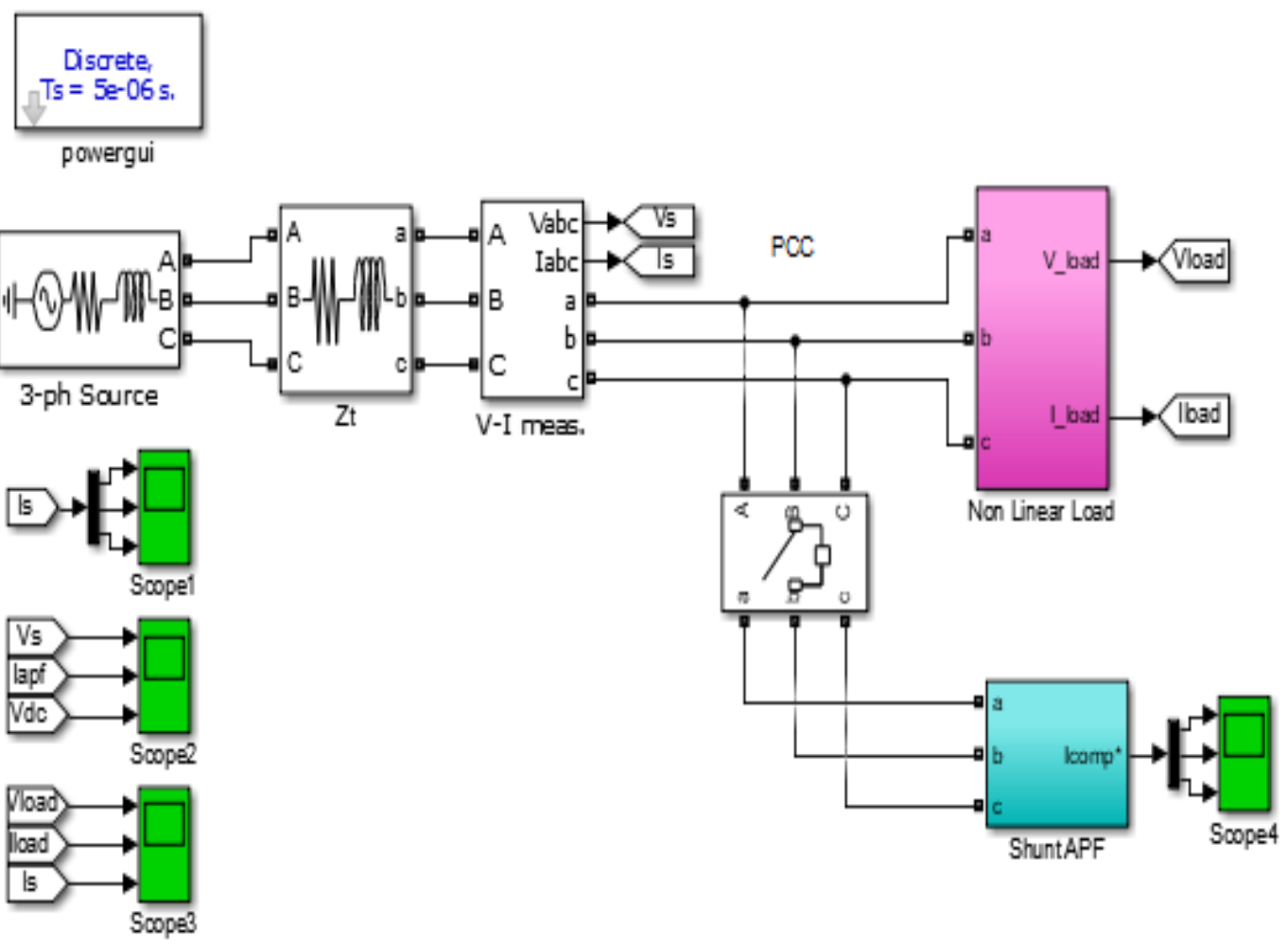

Figure 1. Hybrid Shunt Active Power Filter 


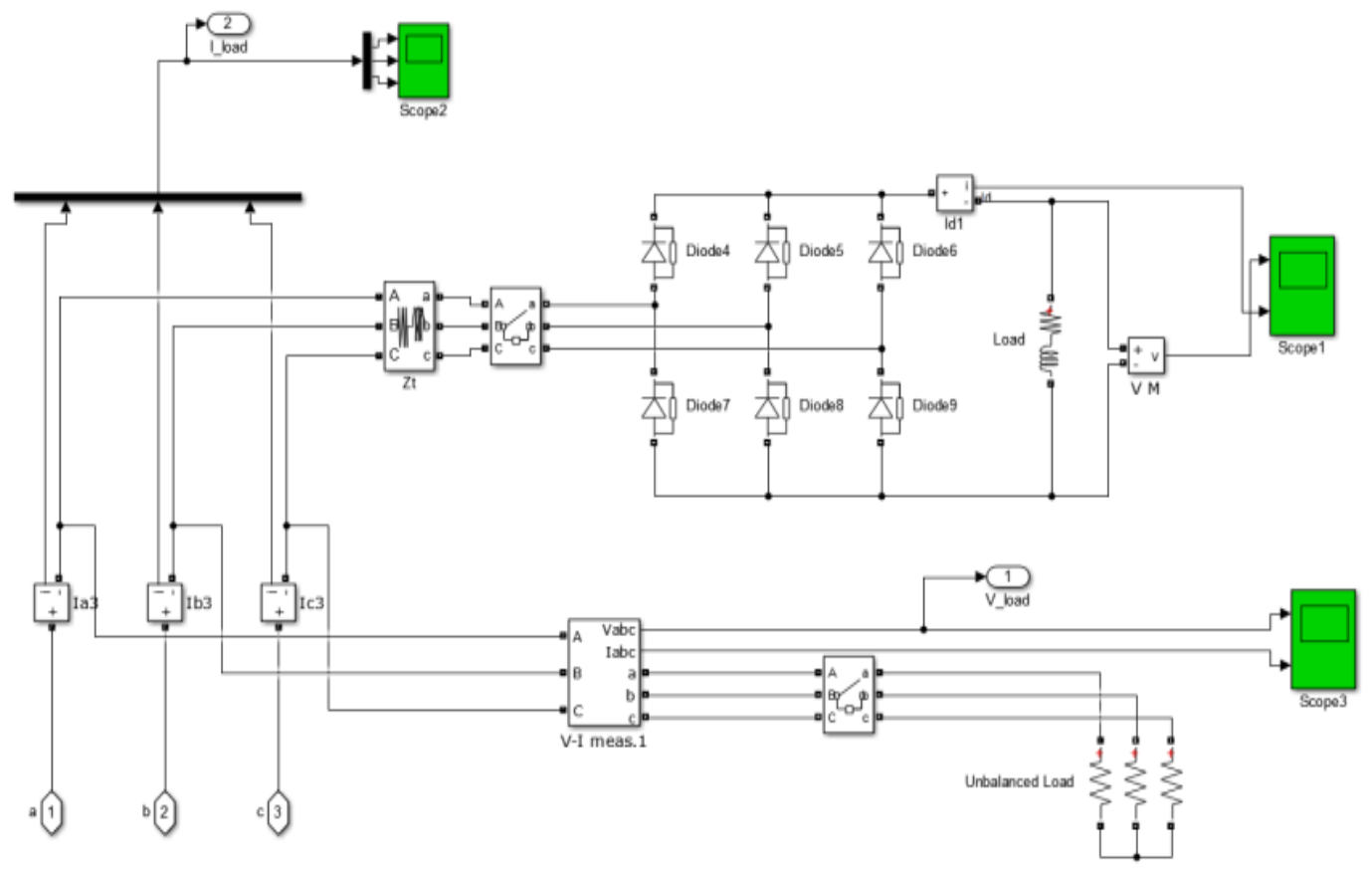

Figure 2. Non Linear Load
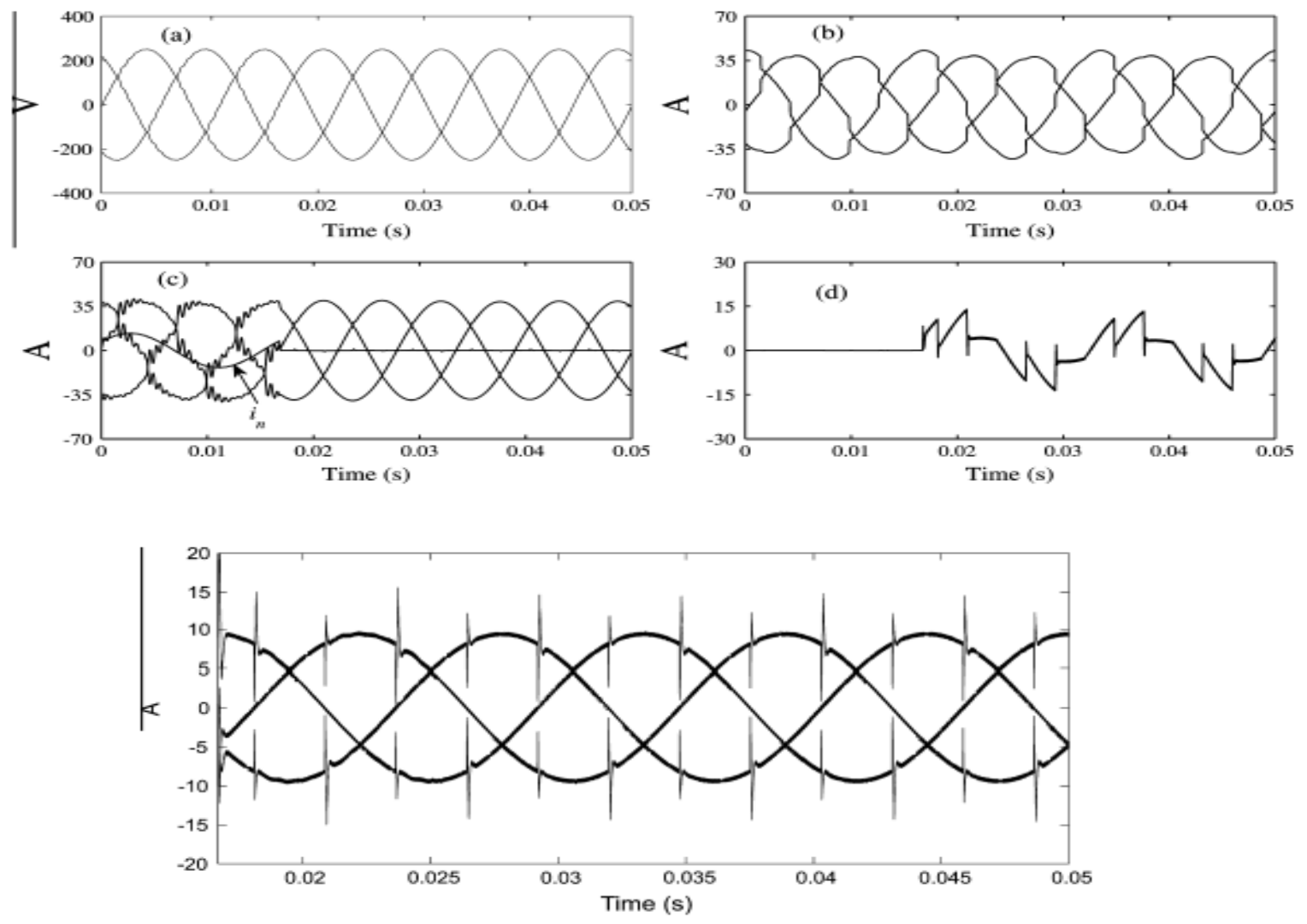

Figure 3. Shunt Active Power Filter 
Under this SHF compensation scheme, the sinusoidal load voltages observed in Figure 3(a) are the terminal voltages across the capacitor. Finally, to complete the analysis of results, the currents through the capacitor. Where it can be observed that the high frequency ripple current has been drained-out thorough the capacitor as it was expected and specified in the control design. The total harmonic distortion of the capacitor current $\left(\mathrm{i}_{\mathrm{ce}}\right)$ was found to be $3.1 \%$, barely increasing the ram's current, due to the harmonic ripple current.

\section{CONCLUSION}

An integrated control for a shunt hybrid filter compensation scheme has been proposed. This integrated control is based on the design of a LQR-based current controller, for a shunt hybrid filter, which has been specifically designed and proposed in this contribution for this SHF scheme of compensation in particular. At the end of the process, the structure of the SHF is composed by a shunt Active Power Filter and a shunt capacitor bank. Obtained results have shown a remarkable performance on the elimination of harmonic distortion (null THD index achieved by the shunt APF) and the compensation of reactive power achieved with a conventional shunt capacitor bank is also companied by using the shunt capacitor bank as a high-pass ripple filter. Therefore, the harmonic ripple current propagation into the electric system has been restricted to a given path... This control action has a very important signification because it provides a sound solution to the potential presence of parallel-resonance associated to the shunt active filtering process, as well as it avoids the harmonic ripple propagation into the electric network, e.g., to the load voltages at the point of common coupling. It has been demonstrated that the proposed control provides a cost-effective solution for shunt active power filtering since transforming the shunt APF into a shunt hybrid filter topology reduces the overall size and cost of the shunt APF due to the size reduction on the KVA rating needed by the electronic power converter of the shunt APF.

\section{REFERENCES}

[1] K. Selvakumar1, et al., "Hysteresis Control 3-Level SI-NPC Inverter with Wind Energy System," International Journal of Power Electronics and Drive System, vol/issue: 8(4), pp. 1764-1770, 2017.

[2] J. M. M. Ortega, et al., "Overview of power electronics technology and applications in power generation transmission and distribution," Journal of Modern Power Systems and Clean Energy, vol/issue: 5(4), pp. 499-514, 2017.

[3] S. Qin, et al., "A high power density series-stacked energy buffer for power pulsation decoupling in single phase converters," IEEE Transactions on Power Electronics, vol/issue: 32(6), 2017.

[4] H. Atria, "Evaluation of selective harmonic elimination pulse width modulation technique for unipolar single -faze H-bridge inverter: comparative study," International Journal of Power Electronics and Drive Systems, vol/issue: 9(3), 2018.

[5] M. N. Morshidi, et al., "Whale optimization algorithm based technique for distributed generatio installation in distribution system," Bulletin of Electrical Engineering and Informatics, vol/issue: 7(30, 2018.

[6] Singh B., et al., "A review of active filters for power quality improvement," IEEE Trans in Electron, vol. 46, pp. 960-71, 1999.

[7] Grady W. M., et al., "Survey of active power line conditioning methodologies," IEEE Trans Power Deli, vol. 5, pp. $1536-42,1990$.

[8] Arêtes M., et al., "Three-phase four-wire shunt active filter control strategies," IEEE Trans Power Electron, vol. 12, pp. 311-8, 1997.

[9] Chang G. W. and She T. C., "A comparative study of active power filter reference compensation approaches," Proc IEEE power eng soc summer meeting, vol. 2, pp. 1017-21, 2002.

[10] Medina A. and Ramos C. H. A., "An active power filter in phase coordinates for harmonic mitigation," IEEE Trans Power Deli, vol. 22, pp. 1991-3, 2007.

[11] Singh B., et al., "Computer-aided modeling and simulation of active power filters," Electra Power Compton Sits, vol. 27, pp. 1227-41, 1999.

[12] Azevedo H. J., et al., "An active power filter with direct current control for power quality conditioning," Electra Power Compton Sits, vol. 36, pp. 587-601, 2008.

[13] Kursk T., et al., "Current reference generator for $50-\mathrm{Hz}$ and $16.7-\mathrm{Hz}$ shunt active power filters," Int J Electron, vol. 97, pp. 63-81, 2010.

[14] Park T. J., et al., "Shunt active filter for reactive power compensation," Int J Electron, vol. 88, pp. 1257-69, 2001.

[15] Patina R. D. and Singh S. P., "Digital signal processor based shunt active filter controller for customer-generated harmonics and reactive power compensation," Electra Power Compton Sits, vol. 38, pp. 937-59, 2010.

[16] Bus S., et al., "Comparison of current control techniques for active filter applications," IEEE Trans in Electron, vol. 45, pp. 722-9, 1998.

[17] Gosh A. and Aldrich G., "Power quality enhancement using custom power devices," Lower Academic Publishers, 2002.

[18] Dejsakulrit D., et al., "A novel equal sampling switching strategy for active power filters," Electr Power Compton Sits, vol. 22, pp. 405-21, 1994. 
[19] Adage H., et al., "Comparisons in circuit configuration and filtering performance between hybrid and pure shunt active filters," IAS Annul Meet, vol. 2, pp. 1195-2002, 2003.

[20] Ghost A. and Aldrich G., "Load compensating DSTATCOM in weak AC systems," IEEE Trans Power Deliv, vol. 18, pp. 1302-9, 2003.

[21] Badrzadeh B. and Gupta M., "Practical experiences and mitigation methods of harmonics in wind power plants," IEEE Trans in Apple, vol. 49, pp. 2279-89, 2013.

[22] Mad H, A. K. N., et al., "Grid harmonic detection and system resonances identification in wave power plant applications," Industrial electronics society, IECON 2013-39th annual conference of the IEEE, Vienna, pp. 16449, 2013.

[23] A. Denis R., et al., "Distributed series/hybrid shunt compensation for harmonic mitigation in commercial facilities," 2014 international power electronics conference (IPEC-Hiroshima 2014 - ECCEASIA), Hiroshima, pp. 3270-7, 2014.

[24] IEEE Std. 519-1992, "Recommended practices and requirements for harmonic control in electric power systems," IEEE Press, 1993.

[25] Singh B., et al., "Hybrid filters for quality improvement," Proc IEE Genre Trans Diatribe, vol. 152, pp. 365-78, 2005.

[26] Choy S. and Jang M., "A reduced-rating hybrid filters to suppress neutral current harmonics in three-phase fourwire systems," IEEE Trans in Electron, vol. 51, pp. 927-30, 2004.

[27] Corasaniti V. F., et al., "Hybrid active filter for reactive and harmonics compensation in a distribution network," IEEE Trans in Electron, vol. 56, pp. 670-7, 2009.

[28] Zola A. F., "Optimal sizing of the passive filter's elements in hybrid active filters," Electr Power Compton Sits, vol. 35, pp. 483-8, 2007.

[29] Venkatesh C., et al., "S-transform-based hybrid active filter for mitigation of current harmonics," Electr Power Compton Sits, vol. 37, pp. 1305-20, 2009.

\section{BIOGRAPHIES OF AUTHORS}

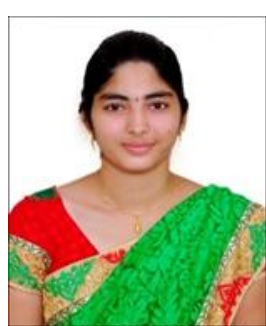

f
Y. Lilith Kameswari was born in Vijayawada, India. She received the Batch (Electrical and Electronics Engineering) degree in Vijay Institute of Technology for Women, JNTUK, India and Match (Power Electronics and Drives) in K.L.University, Guntur, India. She is pursuing Ph.D from Koneru Lakshmaiah Education Foundation, Green Fields, Guntur District, Vaddeswaram, and Andhra Pradesh, India. Her areas of interest are Power Electronics and Power Quality. Presently she is working as Assistant Professor in EEE Department, Reinstitute of Technology, Agiripalii, and Vijayawada. She has 6 Publications in International and National Journals/Conferences.

Dr. O. Chandra Sekhar is currently the Professor and Head of EEE Department in K.L.University, Guntur,Ap, India. He had worked in different capacities in technical institutions of higher learning for a period of over ten years. He obtained B.Tech. and M.Tech. degrees from JNT University, Hyderabad. He obtained Ph.D. in the year 2014 from JNT University, Hyderabad in the area of Modulation and Control of Multi - Level Inverter - Fed Direct Torque Control of Induction Motor Drives. He has over 32 publications in International and National Journals/Conferences. He received prestigious young scientist award from SERB/DST. His current research interests are in Multi - Level Inverters, FACTS Controllers, Micro Grids and Smart Grids. 